she came with a slight return of the disease, for which radium is again being applied. The conjunctiva of both eyes now looks quite healthy and normal. (3) A soldier, who had had one eye removed for injury with shrapnel and in the remaining eye showed a glistening piece of metal just below the macula. V. less than $6 / 60$ and J.16. The eye was quiet and showed no reaction of any kind. The piece had been in the eye for over two months. On the question of treatment, the members present considered it would be best to leave the case alone. (The galvano meter afterwards showed the metal to be non-magnetic.)

By Dr. Gray Clegg:-(1) A case of persistent hyaloid artery complete from the disc to the centre of the posterior surface of the lens. The posterior third was very dark, and appeared to contain blood. (2) A case of tuberculous iritis in a boy, at. 16 years. The patient was admitted into hospital in June, 1916, with keratitis punctata and many grey nodules on each iris. No details of the fundus could be made out. R.V.=J.19. L.V.=Hand movements. He was treated with tuberculin emulsion and received nine injections. In four months there was only one nodule on the right iris and none on the left. R.V.=J.16. L.V.=J. 20. (3) A case of tuberculous iritis in a boy, at. 6 years. Two years ago the left iris was covered with numerous tuberculous nodules. Under treatment with Mehnarto's contratoxin the nodules had entirely disappeared. The iris, however, was lustreless, and the pupil closed. The right eye was healthy.

P. J. HaY.

\title{
ABSTRACTS.
}

\section{I.-QUININE AMBLYOPIA.}

Weeks, John E.-Report of cases of quinine amblyopia, with remarks. Trans. Amer. Ophth. Society, Vol. XIV, Part ii, I916, page 593.

Weeks, of New York, reports three cases (given in abstract below) of amblyopia following the administration of quinine or of its derivatives.

1. A lady, aged 51 years, received about 315 grains of quinine hydrochloride per rectum, and although some of the liquid escaped during the injection, it was thought that about one-half of the quinine was retained. Fourteen and a half hours afterwards, the patient was found to be blind, with dilated pupils. There were complaints of tinnitus and deafness. When examined by Weeks twenty hours after the injection of the quinine, the vision and pupils were as noted. 
The optic discs were very pale and the retinal vessels possessed about two-thirds their normal dimensions. The retina was odematous and pale throughout, except at the macula. The treatment included repeated high, copious, saline enemata; glonoin, 1/100 grain every three hours; strychnine, 1/40 grain, three times a day.

On the following day, the patient could distinguish a bright light ; 24 hours later, she could see hand-movements; and on the third day, could count fingers at 4 inches. Seven days after the sight had failed, it was found that the field of the right eye fell everywhere within the $10^{\circ}$ circle, except on the temporal side where it extended to about $24^{\circ}$, whereas that of the left eye was confined to the $15^{\circ}$ circle. Ten days after the failure of sight, V. 20/30 - ., and on the following day the lumen of the retinal arteries was found to have become irregular and the vessel walls thickened. Improvement in these respects followed the administration of caffein, 2 grains, in addition to the glonoin and strychnine. Forty days after the onset of the amblyopia, the light perception, as tested by Snellen's photometric letters, was 75 per cent. About a month later, Parinaud's photometric bars indicated a light perception of 80 per cent. V. $=20 / 20$ - . The optic discs presented about two-thirds normal capillarity. The retinal arteries had about one-half their natural size, while the veins were but slighly narrowed. The fields for white were still concentrically contracted, but approaching their normal limits. Field for red very small. Reduction in the light sense was believed by Weeks to account for the patient's constant complaint, that she could not see the light, even although vision had become practically normal.

2. A girl of 16 years was treated for pneumonia by the administration in all of 2 grammes of optoquin, spread over 36 hours. Four hours after the last dose, the girl complained that she could not see. Six days later, she began to distinguish light, and in six weeks' time, V. $=20 / 30$. Forty-four days after the onset of the mischief, she was first examined by Weeks. V. $=20 / 30$. Optic discs paler than normal, but not markedly so. Retinal arteries reduced to about one-half their usual size. Walls of the retinal bloodvessels thickened. Fields: R.E. above, $20^{\circ}$; below, $15^{\circ}$; nasally, $20^{\circ}$; temporally, $35^{\circ}$. L.E. above, $25^{\circ}$; below $25^{\circ}$; nasally, $20^{\circ}$; temporally, $35^{\circ}$. The.white fields, estimated about two months after the optoquin had been taken, showed loss of most of the lower halves, more pronounced twelve weeks later, when $V .=20 / 30-$. Colour vision "very indefinite." Light perception about 80 per cent.

3. This is a supplementary report of a case published in 1881 by the late H. Knapp (Archives of Ophthalmology, Vol. X, 1881, p. 220). Briefly, loss of vision followed the administration of quinine by the rectum and the mouth. The patient was seen by Knapp almost a 
year after these occurrences. V. was 20/20, and colour perception was normal: But the optic discs were white, the retinal arteries very small, and there was a moderate concentric contraction of the visual field in each eye. Two years later, quinine was again given, and again the child developed amblyopia and became green blind. The fields were much contracted. She lost her green blindness, and recovered V. of 20/30. The optic discs, however, remained white, the retinal vessels small, and the fields contracted.

The condition when the patient was examined by Weeks, some thirty-eight years after, was as follows.-R.V. 20/30, L.V. 20/40. Vertical nystagmus. The optic discs were almost chalky-white, and the blood-vessels few in number and reduced in size. The fields of vision showed concentric contraction for white and for colours.

S. S.

\section{II.-OPHTHALMOLOGY AND INTRA-CRANIAL DISORDERS.}

(I) Grey, Ernest G.-Studies on the localization of cerebellar tumours. V. The cranial nerves. Bulletin of the Johns Hopkins Hospital, September, I9I6.

(2) Cooke, Clinton T.-The appearance of the fundus oculi in general paresis, maniac depressive insanity and dementia præcox. Ophthalmology, October, 1916.

(3) Elsberg, Charles A.-Intracranial surgery and its relation to ophthalmology. New York State Journal of Medicine, November, 19 I 6.

(1) This is the fifth of a series of papers on the localization of tumours in the posterior cranial fossa, and is based on the analysis of sixty-three cases of intra- or extra-cerebellar tumour, confirmed at operation or on post-mortem examination. The author deals with lesions affecting all the cranial nerves; in this abstract his observations on the optic and oculo-motor (third, fourth, and sixth) nerves only will be referred to. For the purposes of analysis, subtentorial neoplasms are divided into four groups: (1) Unilateral cerebellar tumours; (2) median cerebellar tumours; (3) cerebellopontine (unilateral recess) tumours; (4) median extra-cerebellar tumours.

Optic Nerves.-Although choked disc has long been recognised as a very usual symptom of cerebellar tumour, cases have been reported (and verified by operation) in which it has been absent throughout. In all but six of Grey's sixty-three cases there was definite choked disc ; the fundi in these six cases, with one exception, 
showed minor changes, regarded by the author as indicative of increased intracranial pressure. The tumours in all these six cases. were intra-cerebellar. While choked disc in itself has no appreciable localizing value, it may have some importance in this respect when associated with other signs. Its early appearance and high degree, when accompanied by some of the so-called cerebellar symptoms, afford valuable confirmatory evidence of a subtentorial localization of the tumour.

Oculo-motor Nerves (third, fourth, sixth).-Weakness of the muscles supplied by the third, fourth, and sixth nerves in cerebellar tumours is rarely due to primary involvement of these nerves or their nuclei, but is usually the result of peripheral involvement, of a secondary nature. It is probable that paralysis of the third and sixth nerves is mainly dependent upon the situation of the new growth below the tentorium and the individual configuration of the lower surface of the brain and the base of the skull. For the purpose of localizing tumours in one or other part of the posterior cranial fossa, paresis or paralysis of these nerves has practically no significance.

Nystagmus and impairment of conjugate deviation, although common, appear to have but little localizing value. While defect or loss of conjugate deviation is generally towards the diseased side, paralysis of such movement towards the opposite side has been observed in one case ; in several instances conjugate movements in all directions were restricted. The rule which states that the nystagmus is slower and coarser with the eyes turned towards the tumour is subject to many exceptions. When there is a definite and persistent difference in the size and rate of the jerks, with the eyes in the lateral positions, the nystagmus is usually suggestive of the side of the lesion.

J. B. LAWFORD.

(2) Cooke, of Seattle, analyses the results of ophthalmoscopic examination in 24 cases of general paralysis, 28 of dementia præcox, and 14 of maniac depressive insanity. He enumerates the changes found, chiefly of a minor kind, e.g., pallor of disc, blurring of disc outline, and vascular changes. Changes in the blood-vessels of the retina were noted in 75,65 , and 78 per cent. of the above-mentioned diseases, and, generally speaking, the similarity of the fundus changes in dementia præcox and maniac depressive insanity to those found in general paralysis seems to indicate an identity of ætiology.

A. J. Ballantyne.

(3) Elsberg, of New York City, discusses some of the ophthalmological problems encountered before, during, and after his last two hundred operations for intracranial disease.

Papilladema and its relief by operation.-We do not know why papillodema should occur early in some varieties of expanding intracranial disease and be a late comer in others, where intracranial 
pressure is just as high. In two of Elsberg's patients with huge tumours of the frontal lobes, and in another with a large tumour on the under surface of the right temporal lobe, repeated examination failed to discover any changes in the fundi. In two cases of large growths in the cerebello-pontine angle there was but slight enlargement of the retinal veins, while a small tumour, the size of a cherry, in the angle, caused a most intense choking of the discs, with hæmorrhages. In addition to increased pressure of fluid in the vaginal sheaths of the optic nerve, there must be some additional factor, as yet unknown. In many instances the amount of internal hydrocephalus is concerned, but, on the other hand, there is the fact that some cases of internal hydrocephalus run their course without any change in the discs, or, if there is marked downward distention of the third ventricle, with primary atrophy.

To show how rapid may be the onset of papillœdema and hæmorrhages, the author quotes the case of a woman, admitted with symptoms of midbrain tumour, but without any changes in the fundi. Two days later, she had a papillœdema of $4 \mathrm{D}$. in each eye, with hæmorrhages. Again, a patient admitted with the symptoms of a left cerebellar tumour of six months' duration showed a papillœdema of almost 4 D., and on the following morning both fundi showed large hæmorrhages.

Papillœdema may subside with great rapidity. Thus, in one case mentioned by Elsberg, the swelling was reduced from $6 \mathrm{D}$. to $1 \mathrm{D}$. twenty-four hours after operation, and in another, a swelling of $2 \mathrm{D}$. subsided entirely within four hours after operation for meningeal hæmorrhage.

One of the most frequent questions asked prior to an operation for brain tumour is : Will sight improve or not? The authors experience leads him to believe that papillœdema of short duration, even when very advanced, may after operation disappear, and normal vision be regained. Sudden blindness from acute choking of the discs is usually recovered from after operation. On the other hand, loss of vision from long standing papillœdema is usually permanent. Some vision has been restored in a few patients who had a marked internal hydrocephalus associated with the new growth. "In most instances if vision is lost for 24 hours from the advanced choked discs, it is usually lost for good."

Patients are often first seen when choking of the discs is already marked. In 63 cases of brain tumour the result of the first examination of the eyes was as under:

$\begin{array}{llllll}\text { The fundus was normal in } & \ldots & \ldots & \ldots & 24\end{array}$

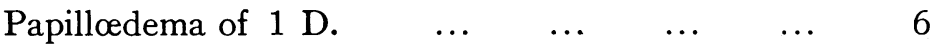

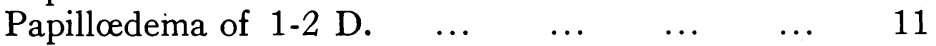

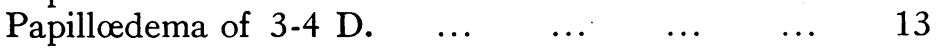

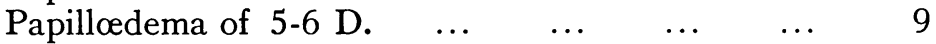


Only 28 of the above patients complained of failing vision, but 39 had more or less well-marked swelling of the discs, and 22 had a papillodema of a high grade. That 62 per cent. of the patients should have sought aid only when they had marked papilloedema, and 35 per cent. only after the swelling of the discs was far advanced indicates that in many cases ophthalmoscopic examinations are put off too long. During the past year Elsberg has twice operated upon a patient with marked papillodema, in whom a very successful operation, with rapid subsidence of the swelling of the discs, failed to save eyesight.

As regards the vexed question, whether there is any relation between the side of the tumour and the papillœdema, the author, in looking over the records of one hundred patients, has found that in fewer than 40 per cent. was the swelling most marked on the side of the neoplasm. In about 60 per cent. of patients with a new growth in one or other frontal lobe, the papillodema was most advanced on the side of the tumour. A study of the post-operative subsidence of the papillœedema brought out certain interesting facts. In 84 per cent. of the patients the papillodema of the eye on the same side as the tumour subsided much more rapidly after the growth was removed than that of the opposite side. If a decompression was done, the papillœdema subsided more rapidly on the side opposite to that of the tumour, unless the latter was located on the same side as the decompressive operation. If a bilateral decompression was performed, then the eye contralateral to the side of the tumour improved more rapidly than its fellow.

The effects of direct pressure upon the nerves and the chiasm and its relief by operation.-Elsberg's experience leads him to agree with Foster Kennedy in claiming that enlargement of the blind spot is especially frequent in tumours of the frontal lobes, and that in a suspected frontal new growth a paracentral scotoma, due to blocking of the more sensitive macular fibres, is of frequent occurrence. His experiences of hypophyseal diseases accord with those of Cushing and Walker. He has met with homonymous hemianopsia, even quadrant defects, in a number of patients. If the fields are tested with small test objects, small quadrant defects in the temporal fields for form, and especially for colour, will frequently be discovered.

It is well-known that patients suffering from hypophyseal disease are often blind of one eye, while the other is still normal or has a well-marked defect in the temporal field. In one such patient Elsberg exposed the sella Turcica, and found that an hypophyseal adenoma had surrounded the chiasm and had also grown around the left optic nerve.

Can sight be regained in an eye blinded from direct pressure on the chiasm, or the optic nerve, when the pressure is removed ?-A 
return of vision is possible as long as the pupil will contract to light. In one of Elsberg's patients with an hypophyseal cyst, with one eye blind for over six months and the other hemiopic on the temporal side, a sellar decompression and evacuation of the cyst were followed not only by great improvement of the hemiopic field, but also the return of some sight in the blind eye. The following case is also of interest in this connection.-A patient, who had been acromegalic for years, after a febrile affection, developed signs of an infection of the sphenoid sinuses, with basilar meningitis and rapid deterioration of vision. Within two weeks the right eye was blind, and the left eye showed a large temporal defect. As the signs of meningitis disappeared after drainage of the sphenoid sinus, sight rapidly returned in the blind eye and the hemiopic field became rapidly enlarged. Both fields were normal _two weeks after improvement had begun.

S. S.

\section{III.-AFFECTIONS OF THE EYE IN DYSENTERY.}

(I) Cosse and Delord.-Some cases of conjunctivitis met with in dysenterics. (Quelques cas de conjonctivite observés chez des dysentériques.) Annales d'Oculistique, janvier, 1917.

(2) Morax, V.-Iritis in the course of a dysentery-like intestinal infection. (Iritis au cours d'une infection intestinale dysentériforme.) Annales d'Oculistique, janvier, I9I7.

The following abstracts refer to affections of the eye in dysentery or in dysentery-like conditions. A case appears to have been made out for the occurrence of conjunctivitis and iritis as metastatic complications of these affections.

(1) Cosse and Delord observed a certain number of cases of conjunctivitis during the course of an epidemic of bacillary dysentery at Chartres in the summer of 1916 . They find no reference to this complication in the literature they have consulted.

The cases are grouped under two heads: 1 . those accompanied by affections of the joints; and 2. those not so accompanied.

1. The first group included eight cases. The symptoms of dysentery were more serious, as a rule, than those of the second group. The conjunctivitis, which lasted for eight or ten days, made its appearance about the fifteenth day of the disease. At this time the articular complications (pain, swelling, and effusion) were observed, and affected chiefly the knees or the tibio-tarsal joints, although the shoulder or the elbow was sometimes involved. The articular lesions lasted for a considerable time, and confined the 
patient to his bed or to his room for several weeks. On occasion, the "rheumatism" preceded the conjunctivitis or accompanied the last-named. Sometimes the enteritis was cured when the conjunctival or articular manifestations declared themselves. In one paradoxical case (Obs. XII) conjunctivitis preceded both the diarrhœa and the affection of the joints. A non-specific bacillus was found in the stools by G. Rosenthal. As to the characters of the conjunctivitis, both eyes were affected at the outset, inflammatory signs were limited to the palpebral conjunctiva, especially to that of the lower lids, and the eyelids were agglutinated after sleep. No follicles or granulations. Glands not involved. Bacteriological examination of the moderate amount of conjunctival secretion, by means of "smears" and cultures, negative. Some cases were treated with argyrol, but more were left alone, and cure was complete in ten days. In one case alone were peripheral keratitis and iritis observed as complications of the conjunctival affection.

2. The second group included four examples of a form of mild conjunctivitis, the stress of which fell almost wholly upon the lower palpebral conjunctiva. It affected both eyes, and made its appearance five to twelve days after the beginning of the dysenteric symptoms. It was associated with a minimal amount of secretion from the conjunctiva. The condition underwent spontaneous cure in six or seven days, or in even a shorter time.

In discussing the conditions described above the authors place wholly aside any question of direct infection, as from fingers or linen. They conclude that the conjunctivitis was of toxic origin and metastatic in character, directly dependent upon the dysentery. They question the propriety of speaking of it as an "inflammation," which implies an infection, and would rather look upon it as a conjunctival manifestation of toxic origin.

Appended to Cosse and Delord's article is a brief account of two cases, where the appearance of articular rheumatism was preceded by mild but definite conjunctivitis.

S. S.

(2) The patient whose case is described by Morax, of Paris, was amongst the sufferers in an epidemic resembling dysentery. This outbreak, which affected nearly 250 men, occurred in barracks. It was characterised by acute enteritis, with frequent and liquid stools, tenesmus, and rise of temperature, and the common association was with articular manifestations. No precise conclusion could be drawn from such bacteriological examinations as were carried out, although the latter, at least, went to exclude amoebic dysentery. Serum treatment met with no success in the several cases where it was tried.

Morax's patient had been affected for about a fortnight when his eyes were noticed to be injected, and to have a little secretion at the inner canthus. About a week later, lively pain was experienced in 
the right foot, to be followed by a similar occurrence in the left foot, the knees, the left elbow, and the sternum being affected a few days later. There was renewed conjunctival mischief involving both eyes. Thirty-five days after the dysentery began, sight became cloudy, and more violent pain set in as regards the right eye, but did not last long. After dilatation of the pupil with atropine, a few small deposits of pigment were found upon the anterior capsule of the lens of the affected eye. A slight relapse of the iritis made its appearance ten days later, to be followed by a third relapse a little later. It is to be noted that the temperature-curve had shown fluctuations at about the periods of the relapses of the iritis.

Morax briefly mentions the case of an officer from Salonika, who had a unilateral and somewhat violent attack of iritis, succeeding enteritis of dysenteric type. He made a good recovery. He also alludes to a case by Vossius (Die ophtalmologische Klinik, 1904, S. 17) of a patient, aged 28 years, who developed in the course of the third week of a typical attack of dysentery, prostatic pain, and a mucopurulent urethral discharge, free from gonococci. Shortly after, he developed conjunctivitis of both eyes (no gonococci), followed by poor sight, and kerato-irido-cyclitis. Normal vision was eventually regained. The dysenteric nature of the general affection was established by the serum reaction; the patient's serum, diluted to $1 / 320$ and to $1 / 1000$, strongly agglutinated Shiga's bacillus.

Following a suggestion recently made by N. Fiessinger and E. Leroy (Soc. méd. des Hôpitaux, 8 décembre, 1916), Morax is inclined to regard the articulo-ocular syndrome of dysentery as analogous to the blennorrhagic syndrome.

S. S.

\section{IV.-HAMORRHAGIC RETINITIS.}

Amsler, Marc.-Contribution to the study of hæmorrhagic retinitis, and especially of its xtiology and prognosis. (Contribution à l'étude de la rétinite hémorragique, notamment de son étiologie et de son pronostic.) La Clinique Ophtalmologique, mai, I9I6 (Abstract from a brochure published at Lausanne by Art et Science, price 2fr. 50).

We may transcribe the author's conclusions as given in this abstract. The original deals, we are told, with the case-histories of 164 cases occurring in 40,000 patients attending the private and public clinics of Professor Eperon. In using the term "hæmorrhagic retinitis," the author explains that he chose it for convenience, without prejudice to the question of actual inflammation of the retina. 
Hæmorrhagic retinitis occurs in 4 per 1,000 cases, and has various ophthalmoscopic appearances. It occurs especially between the years 50 and 70, and more often in women than in men.

It is usually unilateral and seriously affects vision.

It is almost always a manifestation of general disease.

In more than one-half of the cases arterio-sclerosis is the cause. Among the ætiological factors of the remainder are to be found cardiac diseases, albuminuria and glycosuria, arthritism and obesity, the menopause, and, more rarely, influenza.

Not infrequently, the hæmorrhage may be caused by some effort.

The prognosis of hæmorrhagic retinitis is good in 40 per cent. of cases. The favourable factors in these are, the female sex (especially at the menopause between 45 and 60 years); when the hæmorrhages are pre-retinal, that is, hæmorrhagic retinitis in the strict sense, the hæmorrhages being few and peripapillary; a good condition of health, especially as regards the digestive system; appropriate treatment.

The prognosis is bad in 60 per cent. of cases. The following are among the unfavourable conditions, namely, the male sex, advanced age, early arterio-sclerosis, fatigue, overwork, and general weakness.

The appearance of hæmorrhagic retinitis in an arterio-sclerotic subject makes one anticipate cerebral apoplexy. Thrombosis of the central vein is less rare than has been stated $(1$ in 2,000). We believe that its prognosis is not invariably bad.

ERNEST THOMSON.

\section{V.-AFFECTIONS OF THE DUCTLESS GLANDS.}

(I) Lamb, R. S.-The internal secretory system in ophthalmology with special reference to goitre. Annals of Ophthalmology, A pril, I916.

(2) Schirmer, Otto.-Internal secretions and eye diseases. New York State Journal of Medicine, January, I9I7.

(1) Lamb, of Washington, first reviews the literature of his subject, and then states the purpose of his paper, which is: (1) to bring to the attention of ophthalmologists the signs which have been accepted as indicative of certain perversions of the internal secretory system (with special reference to goitre), and (2) at the same time to offer suggestions regarding them, in order to facilitate the identification of these cases, and thereby to obtain an early and 
correct diagnosis of the condition. He believes that thus much suffering may be saved, and chronic invalidism avoided. A factor which complicates all such calculations is the extraordinary interplay in the body between the various glands; an influence which activates one gland may, through an excess of its secretion, stimulate quite another organ to a great increase of activity. The various signs on which Peter lays stress are described each in turn. A number of cases are quoted, and the pathological causes underlying the morbid phenomena are discussed. Finally, the various cases met with are classified, with a view of simplifying the task of those who would wish to follow in Lamb's footsteps.

There are doubtless features in the paper which will arouse the critical faculty of a good many readers; but it is painstaking and suggestive, and is well worth a careful perusal. R. H. ELLIOT.

(2) Schirmer, of New York City, discusses broadly the symptoms and bearings of disordered functions of the so-called "ductless glands." He then speaks of the eye symptoms that may accompany those conditions.

Pressure affections of the optic nerve accompanying disorders of the hypophysis come in for particular notice, and the author lays stress upon the fact that enlargement of the gland may go with over-function, as well as with under-function. Although temporal hemianopsia is the common type of disturbance, there are cases where the visual fields show concentric contraction or homonymous hemianopsia in affections of the hypophysis. He comments upon the powers of resistance often manifested by the fibres of the optic nerve. In other words, pressure may abolish vision without destroying the life of the fibre, as in cases where by surgical or other means pressure has been relieved and sight more or less completely restored. $\mathrm{He}$ mentions the case of passing temporal hemianopsia in multiparæ during the last period of pregnancy (A. v. Reuss). Under such circumstances the hypophysis swells considerably during pregnancy and shrinks as soon as the child is delivered. With every subsequent pregnancy, the gland becomes larger; so that in some cases pressure on the chiasm may occur. It yet remains to be proved that changes in the hypophyseal secretion can produce eye symptoms.

The ocular complications in disturbances of the pineal gland include choked disc, optic atrophy, and anomalies of the eye muscles.

Schirmer thinks it probable that all the eye symptoms of Graves' disease are a direct consequence of the over-function of the thyroid gland. He explains the exophthalmus by an early swelling or even hypertrophy of the fat tissue, which would account for the fact that the symptom often persists after death or in cases otherwise completely cured by surgical intervention. According to Kocher, exophthalmus 
persists in 45 per cent. of the cured cases. The affections of the optic nerve (atrophy and inflammation) in Graves' disease are regarded by Schirmer as the direct result of the toxic action of thyroidin, inasmuch as such are known to have followed the experimental and medicinal administration of that drug.

As to afiections of the eye in tetany, the author puts on one side the single case of optic atrophy reported by Hanke, since the optic nerve has always been found to be healthy in the innumerable instances where the disease has been experimentally induced in difierent animals. The eye muscles, however, sometimes, though rarely, participate in the tetanic spasm-blepharospasm, diplopia, and contraction of the pupil have been observed. Conjunctivitis has followed experimental extirpation of the parathyroids, and has been noted in tetany itself (Falta and Kahn). Schirmer looks upon the associated cataract as due to changes in the epithelium of the ciliary body ; and Peters, indeed, has found microscopical evidence of such in the ciliary epithelium. In children, the cataract of tetany mostly afiects the lamellar type, but in adults it is usually of the cortical type, and may mature rapidly.

Schirmer concludes a suggestive communication by alluding to Abderhalden's method, and outlining some of the work that has been done on those lines, more especially by v. Hippel, to ascertain the condition of the ductless glands in diseases of the eye.

Keratoconus is the one affection of the eye in which the Abderhalden method has given positive results in the great majority of instances. Years ago, it will be recalled, Siegrist claimed that disease as a malady due to under-function of the thyroid gland. v. Hippel's results point in a similar direction. They indicate that in keratoconus the endocrine glands are in a pathological condition. The clinical examination was negative, and especially sexual anomalies were always absent.

v. Hippel also often obtained positive results from the Abderhalden reaction in glaucoma.

Römer and Gebb claim to have found by the Abderhalden method that the biological relation of the lens albumen toward blood-serum is different in cataractous and non-cataractous patients. Abderhalden and v. Hippel have repeated these experiments and have failed entirely to find these differences. Schirmer concludes, therefore, that no new light has so far been thrown upon the ætiology of cataract.

The author ends by suggesting that the study of anomalies of internal secretion will lead to valuable results, not only in the hands of the general physician, but also in those of the ophthalmic surgeon.

Discussion.

Henry H. Tyson, New York City, had reported in 1910 a case of Graves' disease with optic neuritis followed by optic atrophy. 
As to the suggested association between under-function of the thyroid and keratoconus, he had found the opposite condition, namely, over-function, in one case recently, but the keratoconus had antedated the other condition by about six months. He drew attention to a sign that could be elicited early in many cases of over-function of the thyroid gland, namely, a widening of the palpebral fissure upon forced fixation of an object, held midway between and upon the same plane as the eyes, and close to the latter.

Edgar S. Thomson, New York City, regarded the exophthalmus of Graves' disease as due to a low grade inflammatory condition of the tissues. In a man of about 37 years, who had been treated surgically for Graves' disease, with marked exophthalmus, operation was followed by exophthalmus and by a gradual œedema of the ocular conjunctiva of both eyes, so that it eventually became impossible to close the eyelids. Removal of tissue became necessary, and microscopical examination showed an extensive connective tissue hyperplasia, which had gone on to organisation. The exophthalmus remained, and the speaker surmised that a similar tissue change had taken place in the posterior part of the orbit, thus accounting for the protrusion of the eyes.

S. S.

\section{VI.-MYOPIA.}

(I) Koster, W.-On school myopia: its cause and treatment. (Over schoolmyopie haar ontstaan en behandeling.) Nederlandsch Tijdschrift voor Geneeskunde, 1916, Part I.

(2) Pollock, W. B. Inglis.-The reduction of myopia in children of school age. Glasgow Medical Journal, October, 1916.

(3) Sidler-Huguenin.--. Can the development of myopia be arrested and its degenerative changes be prevented? Archives of Ophthalmology, Vol. XLV, No. 6, November, I9I6.

(1) School myopia and progressive malignant myopia are two quite different diseases. Some authors have tried to prove their identity statistically. School myopia is caused by over-exertion and heredity. In Koster's opinion, it is not the direct action of accommodation or convergence that has a bad influence, but these eyes are suftering from a very chronic, slight chorio-retinitis on an hereditary basis. By the effort of accommodation the eyes, especially the posterior parts, are made hyperæmic, and under the combined influence of these two factors, the posterior part of the 
globe becomes ectatic. A logical treatment of school myopia, as considered from this point of view, is (1) against the chronic retinochoroiditis small doses of iodine and salicylates, continued for a long period, avoiding of congestion to the head, and application of radium as far back on the globe as possible; and (2) no over-exertion by reading and writing without glasses, in suitable cases, even with plus glasses.

G. F. Rochat.

(2) The article by Pollock, of Glasgow, on the reduction of myopia in children of school age, is of interest. One must hope that other ophthalmologists will have equally good results. The treatment is that by prolonged use of atropine, associated with removal from school, or, at any rate, with complete cessation of near work. Pollock is fortunate in having to deal with the first School Board in Scotland to introduce the myopia class, namely, the School Board of Govan. The author says that his work in connection with the treatment of myopia began about six years ago with the extension of the use of atropine for testing the refraction. "It is," he says, "common knowledge that after a week of atropine the myopia is about a dioptre less than prior to using the atropine. This change has always been regarded as due to the relaxation of the accommodation, and accordingly no further reduction in the myopia was thought to be possible by continuing the mydriasis. My reason in the first instance for an extended use of atropine was to prevent the patient from doing near work, and thus to give the eyes a more thorough rest; and also, if possible, to prevent a further increase in the myopia. I found, however, that in certain cases after two or three months of treatment the myopia not only stopped increasing, but actually showed a decrease. This induced me to persevere for much more prolonged periods, and the result has been most satisfactory."

It is, of course, true that a great many ophthalmic surgeons must have employed fairly prolonged atropinization in cases of myopia, but, so far as the reviewer is aware, no one has ever published a series of cases showing a reduction of myopia following the use of this or of any other drug, in the least comparable to this series. The cases are four in number. The details follow:-

(1) A girl, aged 7 years, showed by retinoscopy after a week of atropine 11 and $9 \mathrm{D}$., in the vertical and horizontal meridians respectively, in each eye. After two months the retinoscopy was right eye 8 and 6 D., left eye 9 and $7 \mathrm{D}$. One month later, each eye was 7.5 and $6 \mathrm{D}$. Six months later, the right eye was 6 and 4.5 D., the left 6 and $4 \mathrm{D}$. Two months later, each eye had 6.5 and $4.5 \mathrm{D}$. This was the last measurement, on 28th October, 1914. Reduction $4.5 \mathrm{D}$. in ten months.

(2) A girl, aged 9 years, showed, after a week of atropine, 18 and 16 D. in each eye. Seven months later, the right eye had 14 and 
10 D., the left 13 and 9 D. Last examination September, 1914. Reduction 4 D. and 5 D. in R.E. and L.E.

(3) A boy, aged 11 years, after a week of atropine, showed 11 and $6 \mathrm{D}$. in the right eye, and 7 and $2 \mathrm{D}$. in the left. Three months later, the refraction was 8 and $4 \mathrm{D}$. in the right, and 6 and $1 \mathrm{D}$. in the left. Last examination May, 1914. Reduction 3 D. and $1 \mathrm{D}$. in R.E. and L.E. respectively, in three months.

(4) A girl, aged 9 years, presented, after a week of atropine, 13 and $12 \mathrm{D}$. in the right eye and 12 and $11 \mathrm{D}$. in the left. In three months, the right eye gave 10 and $8 \mathrm{D}$., the left 9 and $8 \mathrm{D}$. Last examination February, 1915. Reduction 3 D. in each eye in three months.

Pollock states that he has also obtained a reduction of 3 or $4 \mathrm{D}$. in cases of low myopia and that some of these have become converted into low hypermetropia. Relapses have occurred in some cases during the summer months when the school eye clinics are .closed, and treatment was not carried out.

These are the main facts stated by the author, but he also refers to details of constitutional treatment, to atropine poisoning and atropine dermatitis, and to the well-known difficulty in getting near work really suppressed. The recently instituted myope class has, however, justified all his expectations.

ERNEST THOMSON.

(3) Sidler-Huguenin, of $Z$ urich, propounds the question whether the development of myopia can be arrested and its degenerative changes prevented. As his answer is an unqualified negative, and as it is based on very painstaking work, it cannot be lightly brushed aside, despite the fact that his conclusions are little short of revolutionary.

By the aid of carefully adjusted radiographs, he has satisfied himself that there is no close relationship between the contents of the orbit on one side and the refraction of the eye on the same side; he consequently rejects Stilling's theory. He next considers a series of 150 anisometropes, each of whom practically used only one eye. These patients gradually became more and more myopic in the worse eye, which he states they did not use. From this he deduces that " the use of the eye has nothing to do with the degree or the deleterious consequences of a near-sighted eye." He quotes Steiger in support of his position. Is it a valid argument that because an eye becomes more myopic when its fellow is working, it would equally become more myopic, if both eyes were laid aside from work? In other words, does an eye ever really rest whilst its fellow is working? The answer is almost certainly in the negative to both questions. In the 150 cases quoted there was evidence of heredity of myopia in 18 only. Yet the author says that "we must consider heredity as the most frequent ætiological factor in the development of myopia." 
In 4,000 myopic patients the author found disease of the macula in 218 eyes, and of these 49 had a myopia of less than $10 \mathrm{D}$. This corresponds with Schweizer's results in Haab's clinic. There, in 5,000 myopic eyes, 265 showed macular disease, and in 44 of them the myopia was under $10 \mathrm{D}$. In the 150 anisometropic cases already quoted, corneal changes were present in 78 eyes, whilst in the 4,000 myopes corneal maculæ were present in 187 . The writer is inclined to agree with Meyerhof and others, that the corneal opacity is the cause of the development of the myopia, or, at least, that there is an association between opacity of the cornea or lens and myopia. $\mathrm{He}$ founds this view largely on the fact that in his series of cases a hereditary history of myopia is present in only one of the 78 eyes which showed corneal maculæ: He confesses himself at a loss to explain the causative relationship which he accepts. He suggests that in highly anisometropic eyes, the retina and choroid degenerate rapidly on account of lack of function, but his arguments fail to carry conviction,

He next has something trenchant to say of the bad results which follow the removal of the lens for the relief of high myopia. Again, his view that the use of the myopic eye is probably more favourable than non-use, is based on arguments that will provoke a challenge in a good many minds.

Some stress is laid on the opinions expressed by intelligent patients that a general treatment of their myopia had not affected the course of the eye condition. It may, however, be questioned whether such evidence is of any value whatever. When the writer goes on to say that the usual directions which we give these myopic patients have but little effect, and, again, that myopia gradually increases, irrespective of external influences, to a degree which is dependent upon hereditary factors, one cannot but feel that such fatalism is in excess of what the arguments justify, and that to follow him in practice would be to set back the clock of progress.

On the strength of some very interesting figures, the author has come to the conclusion that "myopia may remain stationary just as well with under-correction as with full-correction," and again, "that full correction is not always capable of preventing the myopia from progressing."

It must be admitted that the writer has had a large clinical material, and has made much use of it, but the pessimism which he manifests towards one and all of the accepted means for the control of myopia will fail to appeal to a great many surgeons. To say that myopia is "a congenital evil which can only be influenced by the proper selection of individuals for marriage," is, from the point of view of practical results, a mere waste of breath. The article is interesting and stimulating; it is the expression of the thoughts of a man who dares to leave the beaten path, and any criticism should 
therefore be offered in a spirit of reluctance and respect. It is certainly a paper which every thinking ophthalmologist should read.

R. H. Elliot.

\section{THE ETIOLOGY OF IRIDO-CYCLITIS.}

(1) Keppeler, Eugen.-Gonorrhœal iritis. Klin. Monatsbl. f. Augenheilkunde, February-March, 1915.

(2) Dernehl, P. H.-Chronic prostatitis a probable factor in iritis. Ophthalmology, A pril, I9I 5.

(3) Reber, Wendell.-Iritis due to influenza. Ophthalmic Record, November, 1915.

(4) de Schweinitz, G. E.-Concerning focal infections in their relation to certain disorders of the uveal tract. Opluthalmic Record, December, 1915.

(5) Reber, Wendell.- Concerning the etiology of iritis as determined by laboratory methods, and its treatment, especially by bacterins. Oplithalmic Record, May, 1916 .

(6) Brown, E. V. L. and Irons, Ernest E. - The etiology of iritis. Transactions American Ophthalmological Society, Vol. XIV, Part ii, I9I6, p. 495.

(7) Francis, Lee Masten. - Recent ideas concerning the diagnosis and vaccine therapy of irido-cyclitis. Report of a case. New York State Journal of Medicine, September, I9I6.

(1) Reviewing the literature of iritis gonorrhoica from the earliest period, Keppeler, of Tübingen, indicates that modern clinical descriptions of the disease have little to add to that given by Mackenzie, of Glasgow (1854). From Mckenzie downwards, most writers agree that gonorrhœal iritis is a disease of acute onset, of great severity (pain, redness, chemois, etc.), with deposits on the cornea and iris, and in many cases (Sidler-Huguenin) a lens-like mass of fibrinous exudate in the anterior chamber. In three of Sidler's cases gonococci were found in the blood, and in one in the aqueous. Other characteristics of the disease are its good and rapid response to treatment, coupled with a relapsing tendency. It affects exclusively males between the ages of 20 and 45 . It is unilateral. Usually other evidences of systemic infection are present, in the shape of articular pains, etc., but these may be absent. That the other parts of the uvea are involved is often proved by the discovery of vitreous opacities after the iritis has subsided. The disease seldom occurs during the existence of an acute gonorrhœal urethritis. It usually appears after the onset of joint affections has indicated the diffusion of the disease. Recurrences are usually preceded by increase of urethral discharge due to exacerbation of a chronic urethritis or by 
an outbreak of articular inflammation. The course is not always favourable. Seclusio and occlusio pupillæ, cataract, and secondary glaucoma may occur.

Local treatment follows the usual lines, and internally we may use quinine, iodides, and calomel. Keppeler specially recommends diaphoresis by means of the salicylates, baths, etc. Other treatment includes the use of gonococcal vaccine, antigonorrhœal serum, and paraspecific serum therapy.

A. J. Ballantyne.

(2) Dernehl, of Milwaukee, reports three cases of males with recurrent iritis, in whom there was a history of gonorrhoal infection. The periods of infection were respectively six, ten, and twenty years before the onset of the iritis. The prostatic secretion was found to contain pus cells and Gram-negative diplococci morphologically similar to the gonococcus but extra-cellular. He inclines to the view that the chronic prostatitis was the cause of the iritis, and that it was gonorrhœal in origin.

A. J. Ballantyne.

(3) Reber, of Philadelphia, reports a case of iritis which was shown to be of influenzal origin by the complement-fixation test, and the rapid relief of symptoms after the use of an injection of influenzal mixed sero-bacterin (sensitised), after failure with salicylates and the vigorous local use of atropine. When the sero-bacterin was discontinued, and the patient placed on mercury and iodide, a violent relapse of the iritis took place. This again gave way promptly to a double dose of sensitised influenzal sero-bacterin.

J. Jameson Evans.

(4). de Schweinitz, of Philadelphia, reviews the subject of infective or toxic uveitis, the broad principles of which were laid down by Brailey and Stephenson some twenty years ago in Norris and Oliver's System of Diseases of the Eye. In connection with oral sepsis, he directs attention to the work of Smith and Barrett, of the University of Pennsylvania, on the relation of parasitic amœba to pyorrhea alveolaris and the production of toxins by their bacteriolytic action. But it is well to remember that "general oral sepsis or extensive pyorrhea alveolaris need not necessarily be present as the instigator of uveitis. The infection may come on from a small tooth-root abscess or from a blind abscess, the presence of which is unsuspected and often undetected until the X-rays are employed."

Other sources of infection referred to are nose, nasal accessory sinuses, tonsils, skin, uterine cavity, prostate, seminal vesicles, and gastro-intestinal tract.

The sources of infection may come from various regions in one and the same subject, and therefore the discovery of a single focal infection should not check the search for septic areas elsewhere in the body.

J. JAMESON Evans.

(5) Reber, of Philadelphia, confesses to a feeling of disappoint- 
ment with current statements as to the ætiology of iritis. The present purely clinical classification into syphilitic, rheumatic, gonorrhoeal iritis, and so forth, is little in advance of that adopted half a century ago. Not only is there confusion as to ætiology, but confusion also prevails as to the relative frequency of each supposed cause. For example, syphilis as the predisposing factor of iritis has been estimated at from as little as 20 per cent. to as much as 70 per cent., and the same is true of the other assumed causes.

Reber believes that with the modern laboratory methods at our disposal, we should be able to get closer to the truth. In determining this point, the history and clinical aspect of a given case must never be neglected; but neither must a so-called complement fixation test or more than one, if necessary. These reactions may be obtained as regards nine micro-organisms, of which five have been shown to bear a causative relationship to inflammation of the iris, namely, (1) the spirochæta pallida; (2) the gonococcus; (3) the pneumococcus; (4) the streptococcus; and (5) the postinfluenzal group.

During the last year, Reber has investigated 15 cases of acute primary iritis, making in every one a complement fixation test for the following: Wassermann, gonococcus, pneumococcus, streptococcus, staphylococcus pyogenes albus and aureus, bacillus coli, and bacillus influenzæ. Of the 15 cases, 5 were syphilitic, both experimentally and clinically ; 3 gave a positive gonococcus reaction, although there was no clinical evidence of gonorrhœa; and 1 was positive to the influenza bacillus. In 6 cases no reaction was obtained, but there were other reasons for thinking that of these negative cases 2 were due to syphilis, 1 to tuberculosis, and 1 to gastro-intestinal toxæmia. Briefly, then, of the series of 15 cases, 33 per cent. were certainly syphilitic and 14 per cent. possibly syphilitic; 20 per cent. were gonococcal ; 6.5 per cent. were influenzal ; 6.5 per cent. were tuberculous ; 6.5 were autotoxic; and, finally, 14 per cent. were of obscure origin. Rheumatic iritis does not figure in the list, and, in Reber's opinion, is destined ultimately to disappear from our text-books and literature.

In conclusion, Reber has something to say about treatment. As regards the syphilitic cases, although he admits the efficacy of salvarsan and neo-salvarsan, yet he has unwavering faith in mercury. If a positive gonococcus fixation test be obtained, the indication for bacterin or vaccine treatment is plain, and if there be arthritic involvement, even in the presence of a negative laboratory examination, Reber recommends the injection of Neisser mixed bacterin. If no cause can be determined, the author feels that the injection of influenza mixed bacterin is justified.

S. S.

(6) Brown and Irons, of Chicago, subjected 100 patients affected with non-traumatic iritis to a most complete examination, physical, 
laboratory, radiographic, etc., in order to determine the cause of the eye mischief. Attention was also paid to the effects of treatment, as indicative of cause. In the course of their investigations they were struck by the large number of cases in which two or more competent causes of iritis were combined in one and the same patient, and they point out the difficulty under these circumstances of deciding the cause of the disease, especially in hospital patients, in whom multiple infections are frequently found.

The causes of iritis, as enumerated by the authors, may be taken up one by one, as follows:-

1. Syphilis. - In 39 cases syphilitic infection had occurred either recently or years before. In 20 of these patients the iritis was obviously syphilitic. Among that number, 13 manifested other clinical evidence of active syphilis. In the remaining 7 the Wassermann reaction was positive in all. Of the 39,3 other cases were probably syphilitic, to judge from the fact that prompt relief followed the exhibition of antiluetic treatment, although other possible causes of iritis were also present. Syphilis as a cause of iritis was commoner $(32.07$ per cent.) in the dispensary patients than in the private group (12.76 per cent.). Finally it may be added that the Wassermann test was applied in 98 of the total 100 patients dealt with in the communication.

2. Dental Infection.-In 41 patients dental infections, demonstrated by radiographs and confirmed by dental surgeons, were found, and in 18 instances this was recognised to be the cause of the iritis.

3. Tonsillar infection.- - Under this heading the authors included deep infections of the tonsils, intra-tonsillar and retro-tonsillar abscesses. On the other hand, slight lesions, such as small crypts containing "cheesy" material, unless accompanied by deeper infection, were not counted. In 16 of the cases of iritis the tonsil was clearly the source of infection: Tonsillar infection was found in several cases of iritis due to other causes.

4. Gonococcal infection. - This was considered to be the cause of iritis in 9 patients, all males. In all, save one, arthritis was present. A positive gonococcal complement fixation test was obtained in 6 of the 7 cases where it was made. In 7 of the 9 cases the iritis was recurrent, and often associated with recurrent arthritis following exacerbations of urethritis. In 7 of the 9 patients infections other than gonococcal were not found. In the other 2 (both recurrent), tonsillar or dental infections were present, but the recurrences were closely associated with exacerbations of urethritis and arthritis.

5. Tuberculosis. - In 8 patients the iritis appeared to be of tuberculous origin. In 7 the evidence was clear, and in 1 presumptive. In 2 of the 7 , active clinical tuberculosis was present, and in 5 positive tuberculin reactions, along with other evidences of tuberculosis, were demonstrated by physical examination and 
radiographs. In 2 cases focal reactions in the eye repeatedly occurred after tuberculin tests. In none of the 7 patients was there any other discoverable focus of infection.

6. Sinus infection.-The authors' experience leads them to believe that there is more difficulty in determining the presence or absence of infection in the sinuses than in any other part of the body. In three of the patients the iritis was considered as due to sinus infection.

7. Other infections. - In 3 cases the iritis was associated with non-venereal infections of the genito-urinary tract, including 2 of the prostate.

8. Combined infections.-In 17 patients there were several possible causes of the inflammation of the iris, and the authors were unable to determine which infection was responsible.

In 1 case no adequate cause for the iritis could be found.

In conclusion, Brown and Irons offer some interesting speculations with regard to the mechanism whereby iritis is brought about. Despite the commonness of focal infections, iritis and other metastatic lesions are rare. It can be produced in animals by the intra-venous injection of bacteria (Stock), which reach the eye by the circulating blood, and which can be recovered from the inflamed organ. The authors have set up iritis in rabbits by the injection into the venous system of streptococcus, B. pyocyaneus, B. mucosus capsulatus, and gonococcus. But large doses must usually be given, so that a condition of sepsis is created, and even then iritis is by no means always produced. By injuring one eye of a series of rabbits by the intra-ocular injection of minute quantities of dead bacteria, and then when the eyes have healed, injecting living staphylococci or streptococci into the veins, they have found that the injured eyes are more liable to infection than the control eyes. Another point to be considered are changes in the infective organisms themselves. In a streptococcal inflammation of the tear-sac, which had presumably caused iritis, the authors were able to produce iritis in rabbits by the injection of the organisms first isolated from the patient. Later cultures, however, yielded negative results.

Finally, we can scarcely do better than quote the authors' closing words :- " It would appear that not one, but several factors are concerned in the production of iritis, among which may be noted the presence of a focus of an infection in which bacteria may live and multiply, partially protected from the living forces of the host; the periodic entrance into the blood-stream of these organisms and their lodgment in the eye, either by reason of their great number, as in sepsis, or by fortuitous embolism; changes in the eye itself, either in vascular anastomoses or in susceptibility of the ocular tissues, owing to previous injury; and, finally, change in the organism 
itself, whereby it may become better able for a time to maintain itself in the tissues of the eye. Such adaptations on the part of the organism do not necessarily imply any demonstrable change in its morphology or cultural reactions."

S. S.

(7) Francis, of Buffalo, speaking of the recent articles upon the ætiology of irido-cyclitis by Wendell Reber: Brown, Irons, and Nadler; and Brown and Irons, clàims that they "blaze a trail in a field which needs exploration, and foreshadow a refinement of diagnosis and therapy which augurs much for ophthalmology." The communications in question have stimulated the appearance of the present contribution.

In searching for the cause of affections of the uveal tract, Francis states that the investigations naturally fall into two groups: 1. the search for a focus from which infection could be transferred to the eye by embolism; and 2. the search for a localized infection in the eye as a part of a generalized systemic process, as syphilis, gonorrhœea, tubercle, etc. Treatment will depend upon which group the condition belongs to. For example, in the first it largely resolves itself into removal of the infective source, as by the extraction of diseased teeth or the enucleation of affected tonsils. In the second group, the co-operation of a laboratory equipped to carry out complement fixation work is essential. The next step is the selection of an appropriate vaccine, which should be autogenous, whenever possible. Failing that, a polyvalent vaccine should be employed. The actual administration of the vaccine should be left to a serologist.

In reference to the value of vaccines, in post-operative infection, Francis relates one very successful case. The patient appears to have developed tonsillitis on the second day after extraction of immature cataract, and coincidently the anterior chamber was partly filled with blood, the iris was muddy, and the pupillary area was " murky." The corneal incision was united, and entirely clear. Ordinary treatment did not improve matters. But within 36 hours of the injection of one half-billion of a mixed polyvalent staphylococcus vaccine, there was a distinct improvement in the state of the eye. Francis regarded the ocular process as embolic from the tonsils.

Francis concludes with the following words:- "Studies such as those of Reber, Brown, and Irons make it quite apparent that the former classifications of the causes of uveal disease must be rearranged and that what has been termed rheumatic iritis is a blanket name covering a group of specific infections. Syphilis likely plays a less prominent rôle in disease of the uveal tract than was formerly supposed. The diagnosis of a particular case entails a consideration not only of syphilis, autointoxication, but the search for a possible focus from which infection may be tranferred to the eye by embolism, 
and particularly the tonsils, alveolar processes, and accessory sinuses. The complement fixation tests for gonococcus, pneumococcus, streptococcus, staphylococcus albus and aureus, B. influenza, B. coli, and micrococcus catarrhalis are now available and should be made, and if a positive reaction is present, the appropriate vaccine should be adminstered. Post-operative or intercurrent surgical infections may offer a field for vaccine. Serologists are agreed that in every instance an autogenous vaccine is safer and more certain than a stock vaccine, but that in some infections the stock vaccines compare favourably in action with the autogenous. The adminstration of vaccine is without danger when in proper dosage and in cases when not clearly contraindicated by serious disease or kidney impairment. Vaccines should be adminstered under the guidance of one trained by experience in their use."

\section{BOOK NOTICES.}

On Blindness in Portugal. (A Cegueira em Portugal.) Dr. Santos. Coimbra, 1915.

Santos, of Lisbon, bases his pamphlet on the prevalence of blindness in Portugal on the census returns from 1864 to 1911. The first census, in 1864, made no return of the number of the blind in the country, and it was not until the second census, taken in 1878 , that any definite statistics on this matter could be obtained. The third census in 1890 was the first in which. a differentiation between those blind in one eye and those completely blind was attempted. The fourth census in 1900, and the fifth in 1911 have been conducted on the same lines as the third.

Statistics drawn from the second census in 1878, disclose the extremely high proportion of nearly one blind in each 500 persons in Portugal ; but as indicated above,' this may not mean absolute blindness, and, as a matter of fact, the returns for 1900 show a substantial reduction of these figures.

The figures in the last census show a slight increase, the numbers agreeing very closely with the results of the enquiries into the number of blind in Portugal made in 1903 and 1904 by Rodriguez and Meyer respectively. The figures for the neighbouring islands of Angora, Horta, Ponta Delgada, and Funchal, show a similar state of affairs.

A comparative table of the numbers of blind in the various European countries is given, but, since the census year differs in the various countries, it does not represent quite accurately the state of affairs at the present time. Russia heads the list with a proportion of $19 \cdot 6$ in 10,000 persons in the census of 1886 ; Portugal comes next with $13 \cdot 2$ per 10,000 in 1911 ; Spain, 11.6; 